\title{
Efficiency and cost analysis of a designed in-line water heating system compared to a conventional water heating system in South Africa
}

\author{
Rupert Gouws \\ Estie le Roux \\ School of Electrical, Electronic and Computer Engineering, North-West University, Potchefstroom, South Africa
}

\begin{abstract}
In this paper, the authors compares the efficiency and cost of a designed in-line water heating system with a conventional water heating system (geyser) in South Africa. The paper provides an overview on water heating systems and heating elements and provides the typical water consumption required by an average household in South Africa. A summary on the design of the in-line water heating system together with a system cost analysis is provided. The designed in-line water heating system takes the energy consumption, temperature and pressure into account during operation. The energy consumption and cost of the designed in-line water heating system is compared to a conventional water geyser. A cost analysis on the designed in-line water heating system, heat pumps and solar water heating systems are also provided. The energy consumption results showed that the conventional water geyser on average consumes $2.5 \%$ more energy to heat one litre of water from $15^{\circ} \mathrm{C}$ to $60^{\circ} \mathrm{C}$, than the designed in-line water heating system to supply one litre of water at $60^{\circ} \mathrm{C}$.
\end{abstract}

Keywords: efficiency analysis, cost analysis, in-line water heating system, conventional water heating system, design and monitoring

\section{Introduction}

South Africa currently faces a number of energy related problems; some of these include environmental sustainability, energy reliability and tariff hikes (Sebitosi, 2008; Sebitosi and Pillay, 2008). It is estimated that the electricity utilization of the residential sector in South Africa accounts for almost $35 \%$ of the peak demand, with water heating con- sumption at approximately $40 \%$ of this peak demand (EDRC, 2003; DEAT, 2004).

It was therefore decided to investigate the in-line water heating system as an alternative to the conventional water heating system (geyser). It was further decided to design an in-line water heating system which has the following capabilities: 1) energy consumption control, 2) low flow compensation, 3) PID temperature control and 4) automatic switch off during no flow.

Figure 1 shows the experimental setup of the inline water heating system and the conventional water geyser. The conventional geyser has a cold water inlet at the bottom of the tank and a hot water output at the top. A thermostat (manually set at $60^{\circ} \mathrm{C}$ ) regulates the temperature inside the tank. The conventional geyser supply hot water to the sink on the right hand side and the designed in-line water heating system supply hot water to the sink on the left hand side.The designed in-line water heating system is equipped with a controller with interactive display (set at $60^{\circ} \mathrm{C}$ ) which is installed next to the sink.

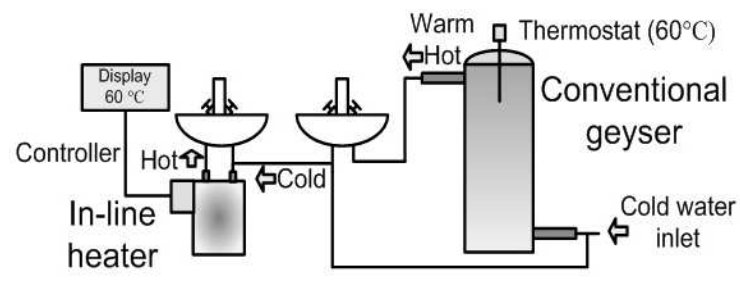

Figure 1: In-line water heating system and conventional water heating system (geyser)

The focus of this paper is on the comparison of the efficiency and cost of the designed in-line water heating system with a conventional geyser. An overview on the design of the in-line water heating 
system together with a system cost analysis is provided in section 3 . The results on the energy consumption of the designed in-line water heating system and the conventional water heater together with a cost comparison between different water heating systems are provided in section 4 . Wilson (1978) provides more detail on the available energy conservation options for residential water heaters.

\section{Overview on water heating systems and elements}

This section provides an overview on the in-line water heating system, the conventional water heating system, heating elements and the required water consumption per person.

\subsection{In-line water heating system}

In-line water heating systems are also know as tankless water heaters, on demand water heaters, instant water heaters, instantaneous water heaters and point of use water heaters. The main two types of tank-less water heating systems available are gas fuelled and electric instantaneous water heaters. For this paper, the focus is specifically on the electric instantaneous water heater.

The basic operational principle of an in-line water heating system is the same as the conventional water heating system (geyser). Cold water flows in and warm water flows out (Rollins, 2010).

The main difference between the in-line water heating system and conventional geyser is that the in-line water heating system has no tank and warm water is instantly available and does not take a long period of time to heat up. Water is also not stored in a large tank throughout the day; there are therefore no standing losses. The most basic in-line water heating system has two coils.

The first is the water carry coil, which carries the cold water into the system, heats it up and then warm water is send through the same coil as output to the user. The second coil is known as the heating coil which is twisted around the carrier coil and heats the water as it passes through (Rollins, 2010). The in-line water heating system consists of different types of sensors to ensure correct and efficient working of the system. When the hot water faucet is turned open, the pressure and temperature sensors are activated.

The pressure and temperature of the incoming cold water are measured and the data is send to a microprocessor for calculations. The microprocessor compares the calculated values with the preprogrammed data and adjusts the heating coil accordingly. The sensor constantly sends data to the microprocessor and the data is constantly monitored and regulated throughout the on cycle of the faucet (Etankless, 2010).

When the faucet is turned off the pressure sen- sor communicates with the microprocessor letting it know to turn off the power and that no more action is required. For the customer's convenience many of these on demand water heating units have a digital display, on which the temperature can be set according to the customer's needs. This functionality can improve the energy consumption of the inline water heating system, if correctly operated.

\subsection{Conventional water heating system}

Figure 2 shows an example of a conventional geyser. The conventional water geysers are designed to heat water and store the heated water in an insulated tank. Every water heater consists of a cold water inlet and a hot water outlet. The cold water is routed through a pipe called a dip tube to the bottom of the heater. In some designs, the cold water inlet is found on the bottom of the tank. When warm water is used, the tank automatically fills up with cold water through a one way valve (ACME, 2010; van Amerongen 1972).

All warm water heaters build up pressure and are therefore equipped with a temperature and pressure (T\&P) relief valve to ensure safe working condition (Klenck, 1997; van Amerongen, 1972). The heating elements are situated in the middle and the bottom of the tank to efficiently provide heating to the tank. Every heating element also contains a thermostat, which switches the heating element on when the temperature drops below a per-set value and off when it rises above the same per-set value. Changing the per-set value is usually avoided, since the geyser is usually located inside or on the roof.

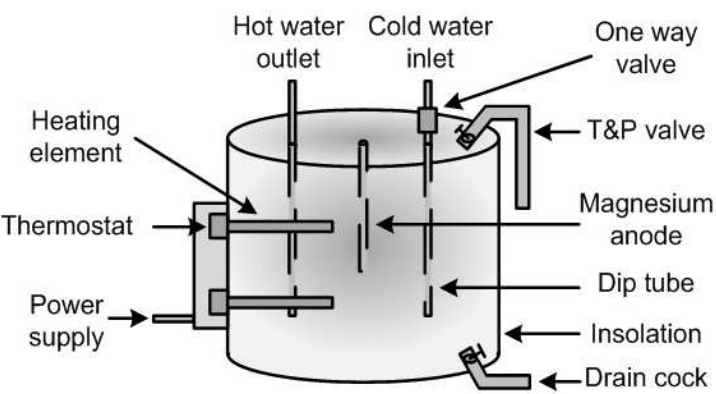

Figure 2: Conventional water heating system (geyser)

The conventional geyser is further equipped with a drain cock, which can be used to empty the tank if required.

Some conventional geysers have two heating elements, which can operate individually. The bottom heating element and thermostat turns on when the temperature drops below the per-set value and the top heating element and thermostat is used as an energy cut off (ECO) device, only switching on when the temperature drops even further (ACME, 2010). 
Sowmy and Prado (2008) provide more detail on the assessment of the energy efficiency of electric storage water heaters.

\subsection{Heating elements}

When designing an in-line water heating system it is important to know what heating elements are available. Heating elements usually range from $150 \mathrm{~W}$ to $4 \mathrm{~kW}$ and are available in the following materials: copper, steel, stainless steel, cast iron, incoloy, titanium and PFA coated (Omega, 2011).

Immersion heating elements are the most commonly known heating elements, which are normally used in geysers, washing machines, sterilizers and other commercial products. The two basic types of immersion heating elements available are over-theside and screw-in (or screw plug) (Omega, 2011). Figure 3 shows examples of these two types of heating elements (Swiftheat, 2011).

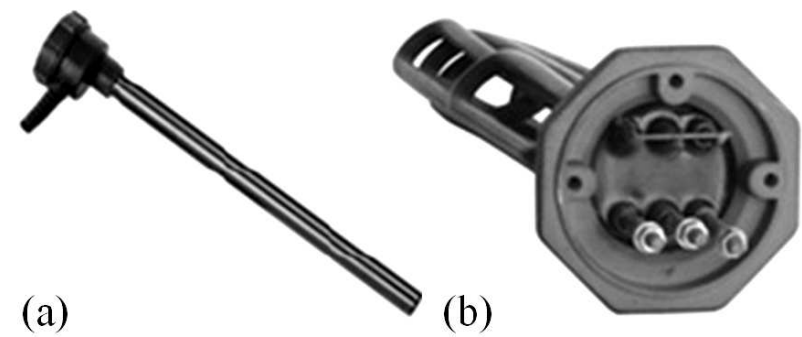

Figure 3: Example of an (a) over-the-side heating element and (b) screw-in heating element

The over-the-side heating elements are designed to hang over the side of a tank and are usually used where the heating element is not able to fit in at the bottom or top of the tank. The sleeve material of the over-the-side heating element is the most important quality to consider when deciding on this product. The sleeve/sheath materials available are: aluminium, brass, copper, fluropolymer, high temperature foil, iron, nickel alloy, polyimide, steel and stainless steel.

Screw plug heating elements consist of tubular elements which can be welded or braced into a screw plug. The element is usually connected to a tank (Tempco, 2011). The sleeve/sheath materials available are: steel, incoloy, copper and 316 stainless steel. The screw plug heating element is usually the most commonly used and affordable.

\subsection{Water consumption}

Water consumption is usually divided into two parts: 1) the total daily water usage per person and 2 ) the total daily only warm/hot water usage per person. For an average household, the consumption is usually multiplied by four (Ilsette, 2010). The average hot water consumption for a household of four is approximately 292.8 litres per day in South Africa. This data must be taken in account when a product such as a geyser or an in-line water heating system is bought or designed.

The location of the in-line water heater or geyser also affects the amount of water being used. In-line water heaters are normally installed as close as possible to where hot water is required, whereas conventional water geysers are normally installed at the centre of a household to provide hot water for the whole household. Normally more than one in-line water heater is installed at a household.

\section{In-line water heating system design and cost analysis}

This section provides a summary on the design and cost analysis of the in-line water heating system. The detailed design and design specifications are provided by Le Roux and Gouws (2011).

For this project, is was decided to build an in-line water heating system with an installed capacity of $12 \mathrm{~kW}$ and compare the cost and efficiency of this system with a 150 litres, $47 \mathrm{~kg}, 600 \mathrm{kPa}$ conventional geyser with an installed capacity of $3 \mathrm{~kW}$. Standard residential in-line water heating systems normally range from $1.2 \mathrm{~kW}$ to $4 \mathrm{~kW}$.

\subsection{Overview on the design}

The components (items) used in the design of the in-line water heating system consists of a PID controller, power inlet at $230 \mathrm{VAC}$, electromechanical relay, contractor, three $4 \mathrm{~kW}$ screw-in type stainless steel elements, three stainless steel cylinders, a PT 100 temperature sensor, a cold water inlet with pressure reducing valve, a warm water outlet faucet with a flow switch mounted inside the outlet pipe and a digital energy meter.

Figure 4 shows the face view of the designed inline water heating system. The left image shows a detailed drawing with the actual measurements and the right image shows the actual system. In this figure, the temperature controller, earth leakage, contactor, flow switch and temperature probe can be seen.

Figure 5 shows the rear view of the designed inline water heating system. In this figure, the three 4 $\mathrm{kW}$ elements and three stainless steel cylinders can be seen. The use of different types of heating elements will increase the overall efficiency, but will also increase the overall system cost.

For this project it was decided to use $4 \mathrm{~kW}$ screw-in type heating elements, since it was the most affordable and was available (in stock) for less than R 120 each.

The heat flow analysis of the stainless steel cylinders was done by using the Cosmosflo tool of Solidworks ${ }^{\circledR}$. Le Roux and Gouws (2011) provide more detail on the heat flow analysis of the designed in-line water heating system. 

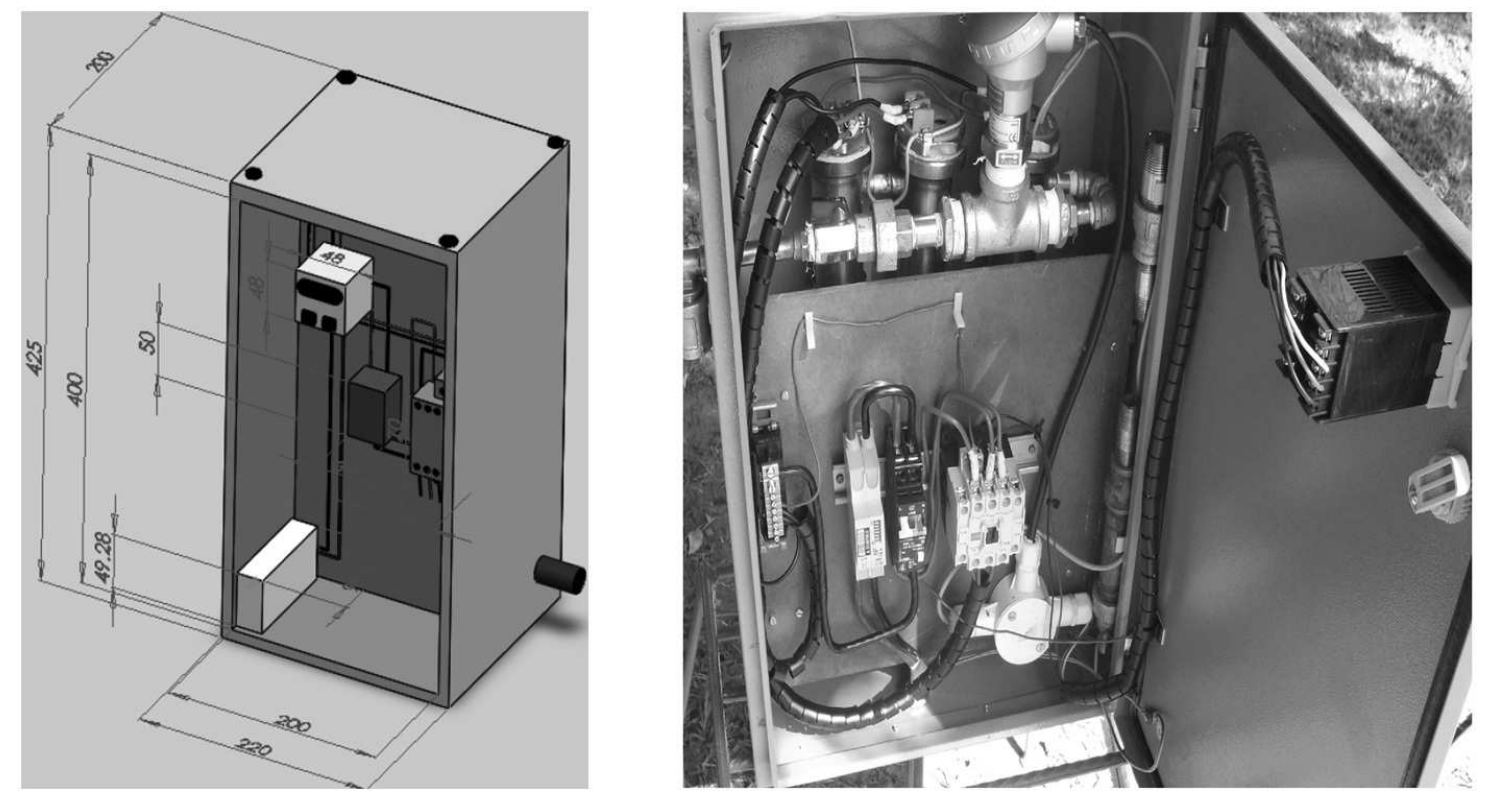

Figure 4: Face view of the designed in-line system (simulated and physical model)
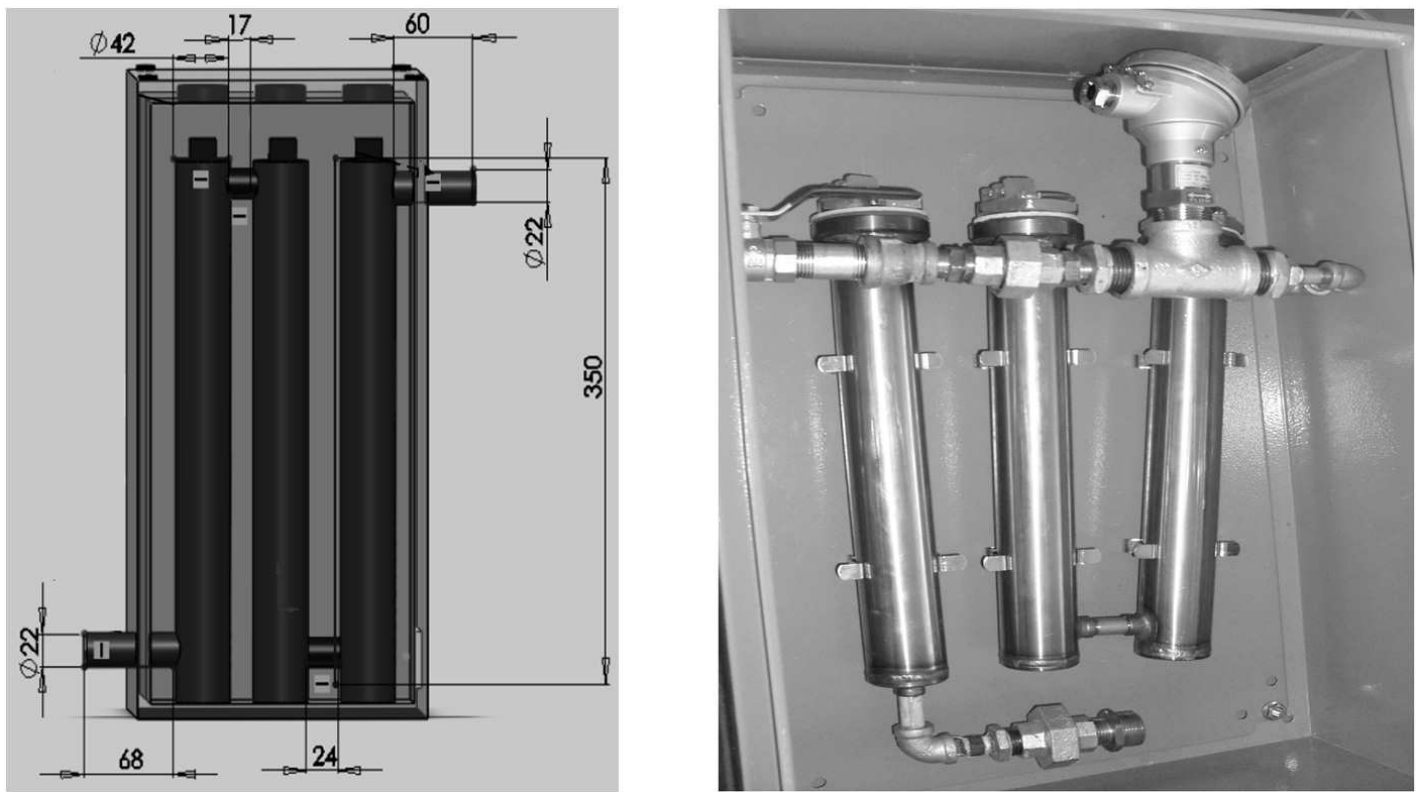

Figure 5: Rear view of the designed in-line system (simulated and physical model)

\subsection{Overview on the temperature controller}

This section provides an overview on the operating principle of the temperature controller for the designed in-line water heating system.

The temperature controller together with the heating cylinders (or heating elements) is the most important components (items) of the designed inline water heating system. The temperature controller has a direct influence on the efficiency of the designed in-line water heating system. For this project, the $\mathrm{CN}-40$ temperature controller from $\mathrm{TOHO}$ Electronics in Japan was selected, since the temperature controller has build in PID control to improve the speed of the response, suppress disturbances and reduce oscillation.

Figure 6 provides the operating flowchart of the temperature controller. When the in-line water heating system is switched off the heating elements and PID controller is also off.

When the system is switched on, a flow reading is taken. When there is no flow, the heating elements and PID controller is switched off. When a flow is detected, the process value (PV) and setpoint value (SV) are measured.

When the PV is not the same as the SV, the PID controller and heating elements is switched on. When the PV and SV are the same, the heating elements and PID controller is switched off. The sys- 
tem returns to the initial measurement and reading block after each cycle.

Throughout this cycle the user is always aware of the energy consumption and can choose to switch to a lower temperature setting (lower SV) to save energy.

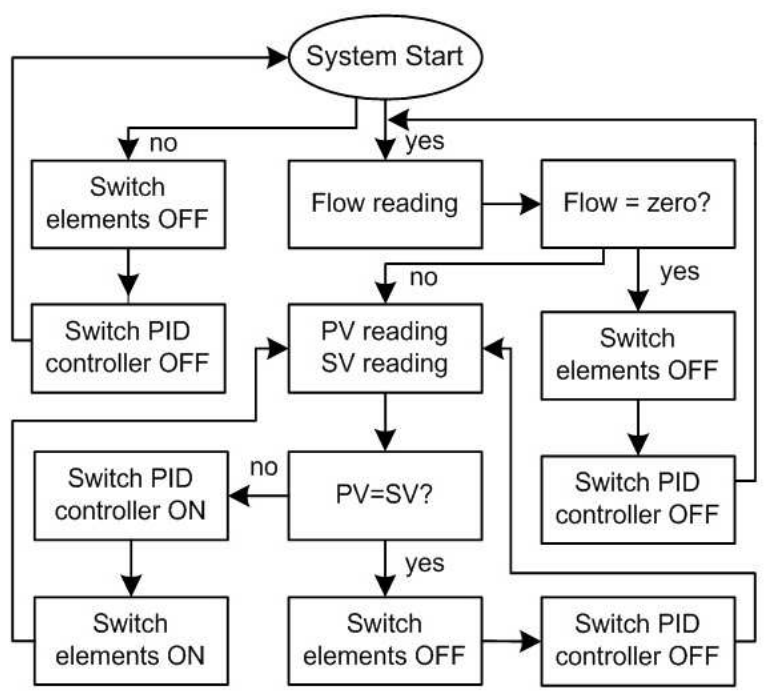

Figure 6: Temperature controller operating flowchart

After the in-line water heating system was successfully build, the system was tested at the maximum flow rate of $8 \mathrm{l} / \mathrm{min}$. The system was able to immediately heat the cold water (at $15^{\circ} \mathrm{C}$ ) to $39^{\circ} \mathrm{C}$. The total power required at this rate was $12 \mathrm{~kW}$ and the total current drawn was $52.17 \mathrm{~A}$.

\subsection{System cost analysis}

This section provides the cost analysis of the designed in-line water heating system. Table 1 presents the breakdown of the total integrated cost of the in-line water heating system. Components (items) were chosen according to minimum requirement, safety, availability and available funding.

The total cost of the in-line water heating system resulted to R3 980.26 including tax at $14 \%$. The system could however, be manufactured at an estimated cost of around R3 000 including taxes, if only two heating cylinders were used in the design process and if the components were bought in bulk.

\section{Results}

In this section, the energy consumption of the designed in-line water heating system is compared to the energy consumption of a conventional geyser. This section also compares the cost of the designed in-line water heating system to other water heating systems.

\subsection{Energy consumption comparison}

The total average current drawn by the designed inline water heating system was measured at $44.6 \mathrm{~A}$ (during the on cycle at a flow rate of $5.022 \mathrm{l} / \mathrm{min}$ ),
Table 1: Total cost of the in-line water heating system

\begin{tabular}{lr}
\hline Item & Price (R) \\
\hline Heating elements with pocket (3 x 4 kW) & 347.49 \\
\hline Flow switch (flow/pump in-line switch) & 520.00 \\
\hline Enclosure (orange stainless steel) & 420.31 \\
\hline Stainless steel cylinders (welding \& pipe) & 1078.00 \\
\hline Temperature controller (CN-40) & 783.00 \\
\hline Temperature sensor (PT100) & \\
\hline Digital energy meter & 195.00 \\
\hline 150.00 & \\
\hline Contactor & 250.00 \\
\hline Earth leakage (additional) & 114.00 \\
\hline Neutral bar and adapter plate & 58.58 \\
\hline Galvanized pipe fittings & 50.00 \\
\hline Miscellaneous fittings & 127.88 \\
\hline Total & 3980.26 \\
\hline
\end{tabular}

while the conventional 150 litres geyser only drawn 16.1 A. The in-line water heating system instantly supplied hot water, while the conventional geyser had to heat 150 litres of water before the same temperature of $60^{\circ} \mathrm{C}$ was reached.

Figure 7 shows the measured profiles of the energy consumption for the designed in-line water heating system and conventional geyser. It can be seen from these profiles that the in-line water heating system follows a linear trend of $y=1.525 x-$ 1.775 and the conventional geyser follows a linear trend of $y=0.6382 x-0.3382$, both with a $R^{2}$ value of more than 0.9988 .

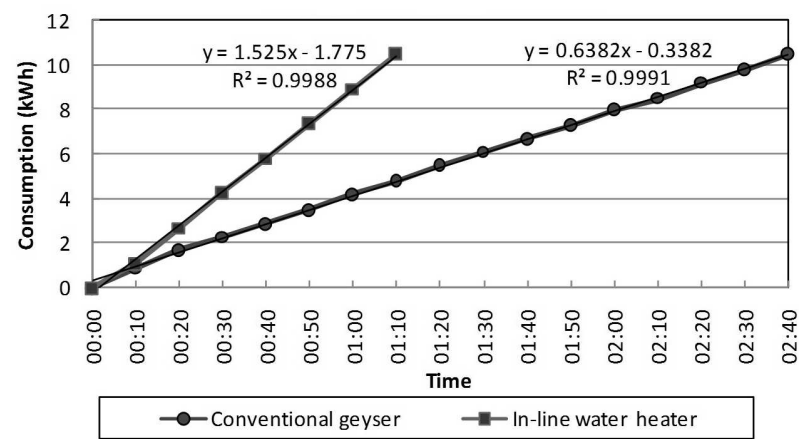

Figure 7: Energy consumption comparison

Table 2 provide a comparison between the measured results of the conventional geyser and the designed in-line water heating system. From this table, it can be seen that the conventional geyser on average consumed $10.5 \mathrm{kWh}$ (over a period of 160 minutes) to heat 150 litres of water from $15^{\circ} \mathrm{C}$ to $60^{\circ} \mathrm{C}$. This means that the conventional geyser on average consumed $26.25 \mathrm{Wh}$ to heat one litre of water from $15^{\circ} \mathrm{C}$ to $60^{\circ} \mathrm{C}$.

The in-line water heating system consumed 10.5 $\mathrm{kWh}$ (over a period of 70 minutes) to supply, on 
average, 351.54 litres of water at $60^{\circ} \mathrm{C}$. The inline water heating system therefore on average consumed $25.60 \mathrm{Wh}$ to heat one litre of water at $60^{\circ} \mathrm{C}$.

The conventional geyser therefore on average consumed $0.65 \mathrm{Wh}$ per litre more than the in-line water heating system. The conventional geyser therefore, on average, consumes $2.5 \%$ more energy to heat one litre of water from $15^{\circ} \mathrm{C}$ to $60^{\circ} \mathrm{C}$ than the designed in-line water heater to supply one litre of water at $60^{\circ} \mathrm{C}$.

The measured data was recorded over a period of a few days and the average consumption was then calculated. The standing losses and long pipe losses therefore have an influence on the measured consumption.

Table 2: Energy consumption comparison

\begin{tabular}{lcc}
\hline & Geyser & In-line \\
\hline Energy consumption & $10.5 \mathrm{kWh}$ & $10.5 \mathrm{kWh}$ \\
\hline Recorded time period & $160 \mathrm{~min}$ & $70 \mathrm{~min}$ \\
\hline Water quantity & 150 litres & 351.54 litres \\
\hline Water temperature & $15^{\circ} \mathrm{C}-60^{\circ} \mathrm{C}$ & $60^{\circ} \mathrm{C}$ \\
\hline Consumption per litre & $26.25 \mathrm{Wh} / 1$ & $25.60 \mathrm{Wh} / 1$ \\
\hline Consumption difference & \multicolumn{2}{c}{$0.65 \mathrm{Wh} / 1$} \\
\% difference & \multicolumn{2}{c}{$2.5 \%$} \\
\hline
\end{tabular}

\subsection{Cost comparison between different systems}

In this section, the cost of the designed in-line water heating system is compared to the cost of the other water heating systems. Table 3 provide the cost comparison between different water heating systems. From this table, it can be seen that the cost of solar water heating systems ranges between R12 000 and R25 000, and are the most expensive. The cost of conventional geysers ranges between R1 300 and R3 000 and are the most affordable. The cost of heat pumps ranges between $\mathrm{R} 8000$ and R20 000.

The estimated cost of the designed in-line water heating system with two heating cylinders is R3 000 and with three heating cylinders is R4 000. The price on each of the systems in Table 3 depends on the installation size and the variables of the situation. Eskom rebates are however, available on approved solar water heating systems and approved heat pumps, but are not available on conventional geysers and in-line water heating systems.

Table 3: Cost comparison between different water heating systems

\begin{tabular}{lc}
\hline Item & Price $(R)$ \\
\hline Conventional geysers & $1300-3000$ \\
\hline Designed in-line heating system & $3000-4000$ \\
\hline Heat pumps & $8000-20000$ \\
\hline Solar water heating systems & $12000-25000$ \\
\hline
\end{tabular}

\section{Conclusion}

Almost one third of household electricity bills are towards hot water energy consumptions, therefore, improvements and research and in this field will be an ongoing process.

During the control phase of the in-line water heating system, the flow rate instead of the pressure was taken into account. This makes the system more adaptable to areas where a low flow is encountered. The pressure values were only used for safety purposes.

For this project, the energy consumption of the in-line water heating system was measured and compared to a conventional geyser. After performing various tests on both the in-line water heating system and the conventional water heating system, the in-line water heating system showed to be more efficient in terms of watt-hour per litre.

The efficiency analysis results showed that the conventional geyser consumed, on average, $2.5 \%$ more energy to heat one litre of water from $15^{\circ} \mathrm{C}$ to $60^{\circ} \mathrm{C}$ than the in-line water heating system to supply one litre of water at $60{ }^{\circ} \mathrm{C}$. The data was however, recorded over a period of a few days, therefore, standing losses and long pipe losses have an influence on the result.

The cost analysis results showed that the conventional geyser is more affordable than the in-line water heating system and heat pumps and the solar water heating systems are the most expensive.

It is estimated that a heat pump can potentially provide three times the thermal energy compared to an electrical geyser, which can result in a saving of up to $67 \%$ in the water heating cost, depending on the size of the installation and the variables of the situation. Solar water heaters can save up to $70 \%$ of your water heating bill, depending on the size of the installation and the variables of your situation.

Apart from the instant and unlimited hot water supply, the in-line water heating system has a number of advantages such as size, adaptability to a variety of locations, and robustness. As with any electrical appliance the consumer can further reduce his or her electricity bill by using the in-line water heating system during off peak periods. Industrial users can preset the unit to deliver a lower temperature during peak periods.

The in-line water heating system can have a lower running cost than the conventional water heating system, if properly managed. The system has no standing losses and no long pipe losses and can save energy and water, if the temperature is correctly chosen. The user can interactively and immediately switch to a lower temperature setting in order to save electricity. It will therefore be possible to only use the correct amount of water (at the correct temperature) with no additional cold water.

The in-line water heating system is a good choice, if hot water is required far from the installed 
geyser, heat pump or solar water heating system.

Prud'homme and Gillet (2001) provide more detail on an advanced control strategy for a domestic solar hot water system with a segmented auxiliary heater and LaMeres et al. (1999) provide more detail on controlling of the power demand of an average residential electric water heater.

\section{References}

ACME, (2010). How does a water heater work. Available at www.acmehowto.com.

DEAT, (2004). A national climate change response strategy for South Africa. Department of environmental affairs and tourism. Available at www.unfccc.int/ files/meetings/seminar/application/pdf/sem_sup3 south_africa.pdf, Pretoria, September 2004.

EDRC, (2003). Electricity consumption in South African households accounts for approximately $35 \%$ of peak demand. Available at www.develop-mentfirst. org/Studies/SouthAfricaCountryStudies.pdf.

Etankless, (2010). Compare electric tankless water heaters. Available at www.etankless.com/comparetankless-water-heaters.php (Accessed: Dec. 2010).

Ilsette P., (2010). SWH information handbook, [Online] Available at ww.cef.org.za. (Accessed: Dec. 2010]).

Klenck T., (1997). How it works: Water Heater. Available at www.popularmechanics.com (Accessed: Dec. 2010).

LaMeres B.J., Nehrir M.H., Gerez V., (1999). Controlling the average residential electric water heater power demand using fuzzy logic, Journal on Electric Power Systems Research, Vol. 52, Issue 3, December 1999, pp. 267-271.

Le Roux E., Gouws R., (2011). Design of an in-line water heating system, North-West University, Project document, Faculty of Engineering, June 2011.

Omega, (2011). Introduction to immersion Heaters. Available at www.omega.com/productinfo/immersion_heaters.html (Accessed: Jan 2011).

Prud'homme T., Gillet D., (2001). Advanced control strategy of a solar domestic hot water system with a segmented auxiliary heater, Journal on Energy and Buildings, Vol. 33, Issue 5, May 2001, pp. 463-475.

Rollins G., (2010). Inline hot water heaters. Available at www.ezinearticles.com. (Accessed: Nov. 2010).

Sebitosi A.B., (2008). Energy efficiency, security of supply and the environment in South Africa: Moving beyond the strategy documents, Journal on Energy, Vol. 33, Issue 11, November 2008, pp. 1591-1596.

Sebitosi, A.B., Pillay P., (2008). Renewable energy and the environment in South Africa: A way forward. Journal on Energy Policy, Vol. 36, Issue 9, September 2008, pp 3312-3316.

Sowmy D.S., Prado R.T.A., (2008). Assessment of energy efficiency in electric storage water heaters, Elsevier Journal on Energy and Buildings, Vol. 40, Issue 12, pp. 2128-2132.

Swiftheat, (2011). Industrial heating elements. Available at www.swiftheat.com (Accessed: June 2011).
Tempco, (2011). Screw plug immersion heaters. Available at www.tempco.com (Accessed: March 2011).

van Amerongen C., (1972). How things work, The Universal Encyclopaedia of Machines, Paladin/ Granada Publishing,

Wilson R.P., (1978). Energy conservation options for residential water heaters, Journal on Energy, Vol. 3, Issue 2, April 1978, pp. 149-172.

Received 12 August 2011; revised 1 May 2012 